O AUTOR

Antônio Albino Canelas Rubim

Professor Titular do Departamento de Comunicação da Universidade Federal da Bahia. Ex-diretor da Faculdade de Comunicação. Expresidente da Associação Nacional de Pós-graduação em Comunicação-COMPÓS. Pesquisador do CNPq. E-mail:rubim@ufba.br.

\title{
POLÍTICA CULTURAL NA CONTEMPORANEIDADE
}

$\mathrm{Na}$ balança entre o público e o privado, Estado atua para a expressão cultural criativa do conjunto da população

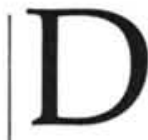

iante das transformações em curso, formular uma resposta à pergunta sobre a possibilidade de uma política cultural sintonizada com a contemporaneidade adquire uma densidade excepcional, derivada da complexa rede de relacionamentos e de alterações societárias acionadas. Esse texto tem como pretensão esboçar um itinerário para o enfrentamento desses desafios, conformados pelas presentes mutações.

Uma reflexão sobre o tema da política cultural no mundo contemporâneo exige, antes de tudo, a introdução de algumas premissas, que dêem um balizamento inicial às argumentações e às discussões a serem desenvolvidas. Para iniciar, podese partir de uma apropriação livre das sugestivas percepções de Antonio Gramsci' ${ }^{1}$ em seu estudo sobre o tema dos intelectuais. Gramsci, além da sempre lembrada distinção entre intelectuais tradicionais e orgâni$\cos$, elabora uma outra tipologia de intelectuais, igualmente plena de desdobramentos elucidativos. Ele diz de outros três tipos de intelectuais: aqueles que criam, como os artistas e cientistas; os que organizam a cultura, dentre os quais podem ser destacados os gestores e os produtores culturais e, por fim, aqueles que difundem a cultura, tais como os educadores e os profissionais de comunicação (na época Gramsci só falava de jornalistas, pois as mídias ainda se encontravam em uma fase rudimentar de desenvolvimento).

Os três tipos de intelectuais, anunciados por Gramsci, podem, por uma fácil ilação, ser considerados como imprescindíveis

1. GRAMSCI. Antonio. Os intelectuais e a organização da cultura. Rio de Janeiro: Civilização Brasileira, 1978. 
para a existência de um sistema cultural. O sistema, em verdade, não poderia funcionar sem o concurso de qualquer dos tipos de intelectuais, ainda que, muitas vezes, em um conhecimento impregnado pelo senso comum, apenas o primeiro tipo - o criador - seja nomeado com o termo intelectual. Um sistema cultural não pode subsistir alicerçado somente nesse tipo de intelectual. Sem organizadores e transmissores/ divulgadores, o sistema cultural não tem possibilidade sequer de formar-se. Logo a cultura entra em colapso e não se realiza.

Cabe afirmar, então, que um sistema cultural necessariamente demanda $\mathrm{e}$ comporta, pelo menos, três momentos e movimentos imanentes: a criação; a organização (aqui incluída a preservação) e a divulgação ou transmissão culturais. Cada um desses três setores historicamente adquire complexidade, constituindo instâncias com crescente especialização, institucionalização e mobilização de recursos (humanos, financeiros etc.). Ao adensamento deve ser acrescido o relacionamento progressivamente mais multifacetado entre os segmentos, constituintes do sistema cultural. O resultado desse processo no presente não poderia deixar de ser um sistema altamente complexo. Uma política cultural consistente tem obrigatoriamente que contemplar todas essas dimensões e seus vitais inter-relacionamentos, sob pena de padecer de mortal incompletude.

Outra constatação essencial: uma política cultural, que se pretenda atual, deve encarar a diversidade de instâncias e atores hoje envolvidos com o tema da cultura. O Estado, este velho agente cultural, deve ser compreendido em sua complexi- dade, como abarcando seus três poderes: o executivo, o legislativo e o judiciário. Tais poderes têm específicas modalidades de interação com o mundo da cultura. A iniciativa privada abrange tanto os setores voltados à produção cultural, a exemplo das indústrias da cultura, quanto aqueles segmentos distantes do campo cultural, mas que, na atualidade, podem manter relacionamentos diversos com este campo, através de dispositivos como o mecenato, o marketing cultural etc. A sociedade civil organizada, seja ela vinculada ou não ao campo dos bens simbólicos, também aparece como ator significativo na atualidade, seja como produtor, estimulador, demandante ou consumidor culturais. Os públicos, com traços bem diversificados, sejam eles amplos ou restritos, especializados ou não, jogam papel considerável na dinâmica cultural contemporânea. Os profissionais da cultura, de ramos muitos distintos e com caracteres desiguais, têm papéis imprescindíveis de sujeitos nessa dinâmica. Sem considerar este complexo e tenso conjunto de atores e respectivos interesses, nenhuma política cultural pode estar sintonizada com a atualidade, muito menos pretender enfrentar com desenvoltura seus desafios.

\section{CONTEXTO DA QUESTÃO}

A atualidade se apresenta sob o signo de profundas alterações, que permeiam todas as dimensões de sociabilidade. Se vivemos ainda no capitalismo, ele encontra-se em substantiva e, por vezes, surpreendente mutação. Autores, como Fredric Jameson, chegam a falar em um 
"capitalismo da informação", uma nova etapa do capitalismo. Aliás nomeações do contemporâneo recorrendo a signos da comunicação e da informação têm sido recorrentes na bibliografia recente ${ }^{3}$.

Mas o contemporâneo se afirma ainda vivenciado como uma sociabilidade subjugada ao modo de vida capitalista.

Apesar de todas as ameaças e impasses que atingiram o capitalismo no séculos XIX e XX, não se pode esquecer as modificações acontecidas e em curso nessa formação sócio-econômica, pois a pertinência das políticas culturais depende de sua capacidade de amoldar-se à atualidade e considerar seus novos desafios.

Considerar o processo de globalização em andamento não implica, sem mais, não perceber seu desenvolvimento combinado e desigual, para utilizar uma estimulante expressão de Trotsky. A globalização comporta ritmos bastante diferenciados, considerados os territórios ou os campos sociais atingidos. A cidade-metrópole destaca-se como lugar, por excelência, de experimentação dos fluxos mais acelerados de globalização.

As alterações que decorrem de seu movimento podem também ser percebidas mais incisivamente em um patamar econômico. Ela atinge de modo muito distinto tanto os territórios envolvidos, quanto os diferentes setores econômicos, a exem- plo do capital financeiro, industrial etc. Mas suas repercussões se fazem sentir por todos. Uma política cultural atualizada não pode desconhecer as injunções de uma vida econômica cada vez mais globalizada ainda que em ritmos muito desiguais.

O campo político igualmente tem sido impactado por mutações significativas. Ainda que o processo de globalização neste campo tenha percalços mais pronunciados, não resta dúvida de que a política também se encontra afetada pelas novas circunstâncias societárias. O lugar do Estado-nação, dos partidos políticos e dos parlamentos, instituições chaves da política na modernidade, encontra-se, pelo menos, em questão e seus funcionamentos estão passando por nítidas reconfigurações. Em uma rápida e panorâmica visão do quadro de mutações da política não podem ser esquecidos: a emergência de novos atores políticos, locais e globais, como as Organizações Não-Governamentais ONGs e mesmo a sociedade civil ${ }^{4}$ e o surgimento de demandas "regionais", com seus dispositivos macroestatais, como acontece nos blocos que hoje reúnem países em lugares específicos do planeta, a exemplo da Comunidade Européia, ou com as delimitações de fronteiras de regiões autonomizadas dentro de estados nacionais, tais como a Catalunha, o País Basco etc. na Espanha. Essas mutações políticas, têm vital incidência sobre as políticas culturais na atualidade.

A dinâmica que simultaneamente produz a mundialização da cultura, para utilizar o termo reivindicado por Renato

\footnotetext{
2. JAMESON. Fredric. Pós-modernismo. A lógica cultural do capitalismo tardio. São Paulo: Ática, 1997.

3. RUBIM, Antônio Albino Canelas. Contemporaneidade como idade mídia. In: Interface. Botucatu, 4 (7):25-36, agosto de 2000.

4. VIEIRA, Liszt. Cidadania e globalização. Rio de Janeiro: Record, 1998.
} 
Ortiz $^{5}$ e o florescimento de (múltiplas) culturas locais, como enfatiza Mike Featherstone ${ }^{6}$, introduz e dá sentido ao debate da diversidade contemporânea das fontes identitárias, não mais circunscritas às modernas identidades de nação e de classe social ${ }^{7}$. A pluralidade de possibilidades de identidades, característica do contemporâneo, cria um turbilhão de potencialidades com a inauguração de inéditos e inesperados textos culturais. Daí a persistente idéia de um multiculturalismo ${ }^{8}$ como signo e horizonte do presente.

A mundialização da cultura se faz, em impressionante medida, através das potentes e cada vez mais gigantescas indústrias da cultura não propriamente adeptas ou comprometidas com nenhum multiculturalismo. Antes pelo contrário. A idéia de que a lógica da indústria cultural, perspicazmente detectada e expressa por Adorno e Horkheimer ${ }^{9}$, teria perdido poder de iluminação para esclarecer o contemporâneo, parece suspeita. Como não recorrer a este conceito em um mundo no qual, como nunca, o capital organiza cada vez mais a cultura e o mercado se torna universal, transformando tudo em mercadoria, como em um transmutado toque de Mídias? Não parece demais lembrar o sem número de fusões recentemente acontecidas entre as gigantes indústrias do mundo da cultura, nem relembrar que até bem pouco tempo alguns dos mais potentes meios de produção e distribuição de bens simbólicos, como a televisão, o rádio e até o cinema, estavam sob o estrito controle estatal em significativo número de países, dentre eles muitos estados nacionais do Ocidente e do Leste europeu. Agora a maioria deles pauta-se por padrões capitalistas, funcionando em uma nítida lógica de indústria cultural.

No âmbito cultural outro movimento, vital para entender a contemporaneidade, não pode deixar de ser enfocado, ainda que rapidamente, neste panorama das mutações do capitalismo na atualidade.

A subsunção da produção cultural ao capital e sua expansão industrial acentuaram de modo crescente a dimensão de entretenimento contida na cultura.

Com isso, o esforço exigido pelo trabalho cultural parece dar lugar a uma assimilação leve, e mesmo plena de divertimento, da cultura. A cultura parece convergir para o lazer. Não por acaso, cultura, entretenimento e turismo conformam um amálgama poderoso na situação contemporânea ${ }^{10}$. Também essas transmutações não podem ser desconsideradas ao se pensar uma política cultural que se reivindique inscrita na atualidade.

As alterações acontecidas no plano das idéias, dos valores e das sensibilidades afetam indiscutivelmente tais políticas. A

5. ORTIZ, Renato. Mundialização e cultura. São Paulo: Brasiliense, 1994.

6. FEATHERSTONE, Mike. O desmanche da cultura. Globalização, pós-modernismo e identidade. São Paulo: SESC/ Studio Nobel, 1997.

7. HALL, Stuart. Identidades culturais na pós-modernidade. Rio de Janeiro: DP\&A, 1997.

8. SEMPRINI, Andrea. Multiculturalismo. Bauru: Edusc, 1999.

9. ADORNO, Theodor e HORKHEIMER, Max. A dialéctica do esclarecimento. Rio de Janeiro: Jorge Zahar, 1985.

10. FARIAS, Edson. Ócio e negócio: festas populares e entretenimento - turismo no Brasil. Campinas: Instituto de Filosofia e Ciências Humanas - Unicamp, 2000 (tese de doutoramento). 
prevalência do discurso neoliberal como "pensamento único" e sua conseqüente imposição de valores e sensibilidades (ou falta delas) hegemônicos não pode ser descuidada. Mercado, competição, eficácia, produtividade parecem ser o norte que orienta "a totalidade da vida". Por que não também a cultura?

Uma sociabilidade marcada por um espaço planetário e um tempo real não pode ser menosprezada em uma reflexão sobre a cultura e as políticas possíveis e pertinentes que pretendem incidir sobre ela. Aqui transparecem com toda a força as "revoluções" dos transportes e especialmente das comunicações. A atualíssima convergência tecnológica entre comunicação, telecomunicações e informática remodela o mundo. Não seria nada surpreendente pensar a contemporaneidade agora como uma Idade Mídia.

Nesta nova circunstância societária, as mídias transformam-se em estrutura e ambiente da sociabilidade. Poderosas, elas perpassam todas as dimensões sociais e deixam nelas suas cruciais marcas. Impossível pensar hoje a cultura sem um enlace vital com as mídias.

Não por mera casualidade, o campo de estudos da comunicação tem se tornado, por excelência, um dos lugares mais férteis e adequados para refletir sobre a cultura e, em sequiência, sobre as políticas possíveis de serem formuladas e implementadas nesta área.

\section{ENFRENTANDO DILEMAS}

Começar pela discussão acerca do Estado parece recomendável não só pelo lugar que ele tem ocupado na história das políticas culturais, desde a Antigüidade clássica, como também pelo papel que ainda hoje desempenha na maioria das situações, malgrado a ideologia neoliberal que pretende eclipsar por completo seu desempenho. Por certo, sua atividade cultural guarda distinções acentuadas, como pode ser percebido, em uma mera comparação entre a tradição de atuação estatal francesa e a intervenção estatal restrita, como no caso dos Estados Unidos. Mas o ideário hoje em voga, em momentos neoliberais, parece decretar a obsolescência de qualquer política estatal. Tal ideário encontrase totalmente destituído de rigor e mesmo de sinceridade. A atuação estatal está de tal modo consolidada em um conjunto de dimensões que somente um insensato poderia, propor seu desmantelamento e argüir sua ineficácia total.

Parece óbvio que as experiências históricas de autoritarismo, ou mesmo totalitarismo estatal e seu assustador obscurantismo cultural, seja dos nazifascistas, seja dos comunistas, seja de qualquer tipo de ditadura, interditam de antemão a aceitação do Estado como ente onipresente e único legítimo na definição de políticas culturais. O clientelismo, mesmo em situações de democracia, igualmente inibe a prevalência de uma qualidade cultural, ao subjugá-la a critérios politiqueiros. Mas isso não pode significar, em um pólo oposto, eliminar a atividade cultural do Estado.

Antes, trata-se de redefinir seu lugar em uma ecologia do sistema cultural, na qual o Estado deve ocupar um lugar bastante preciso e acordado com a sociedade, com os diversos atores político-culturais envolvidos. Como desconhecer a atividade do Estado na transmissão da cultura (através do sistema escolar-universitário), no apoio à criação da ciência (em especial, pura) e das artes (com destaque para as experimentais e aquelas destituí- 
das de apelo de público) e seu papel na organizaçãoe preservação da cultura, por intermédio de museus, arquivos, sítios históricos etc.? Será possível prescindir desta atuação em todas as áreas? O bom-senso faz crer que não.

\section{A simples retirada do Estado}

\section{pode trazer seriíssimos prejuízos}

para um sistema cultural.

A propalada intenção de desativação de universidades federais em diversos estados brasileiros - supostamente aquelas sem mérito acadêmico para continuar a existir - desconhece um dado vital: o essencial papel cultural que estas universidades desempenham em suas regiões. Supor que o mercado poderia substituir o Estado em todas ou mesmo na maioria das áreas culturais significa não distinguir o joio do trigo. Isto é, não ser capaz de separar uma atuação perversa do Estado, expressa em tintas autoritárias ou clientelistas, e uma atividade positiva e necessária. Mais que isso, pode significar ver morrer de inanição um conjunto de áreas da cultura que não interessam ao mercado, pois não têm potencial de gerar lucros - cultura mercantilizada - e/ou de ter efeitos de marketing para uma produção de imagem institucional.

As inúmeras leis de incentivo à cultura, através de renúncia fiscal do Estado, podem, se imaginadas dentro de um ideário pronunciadamente anti-estatal, ter efeitos perversos, pois terminam por colocar o poder de decisão sobre o uso de recursos majoritariamente públicos - posto que nessas leis os percentuais de recursos públicos sempre estão em proporções maiores que das empresas - sobre o controle privado.

O Estado abdica do controle não em prol de uma decisão e seleção culturais mais qualificadas e democráticas, mas de atos informados por um poder com interesses ainda mais particulares e menos universais.

O tema do marketing cultural remete à presença cultural da iniciativa privada, especialmente aquela não vinculada diretamente ao campo simbólico. A relação entre setores privados e a cultura tem longa história. Talvez um de seus exemplos mais marcantes tenha sido o Renascimento italiano ${ }^{11}$. Mas ainda hoje ele subsiste em alguns países como relevante tradição. Um bom exemplo nesse caso podem ser os Estados Unidos. Diferente desse mecenato privado, no qual o mecenas acolhe criadores culturais buscando tão somente usufruir de prestígio, demonstrar seu poder social ou ostentar sua riqueza, em uma atitude aproximada, por vezes, da filantropia, a modalidade de relação cada vez mais predominante hoje entre a iniciativa privada e a cultura tem sido denominada de marketing cultural ${ }^{12}$.

Neste caso, a relação expressa interesses bem mais precisos: a empresa apóia a cultura buscando um retorno em termos de imagem pública institucional, que traga dividendos para a empresa. A troca torna-se manifesta, o que não exclui necessariamente a existência de uma responsabilidade social assumida pela empresa, podendo mesmo reforçá-la. Mas, com as leis de incentivo fiscal, hoje em moda, a parte

11. A atuação da famflia Medici em Florença, nesse sentido, parece exemplar. Ver: WINSPEARE, Massimo. Los Medici. La edad de oro del coleccionismo. (Os Medici. A idade de ouro do colecionismo.) Livorno: Sillabe, 2000. 12. RUBIM, Antônio Albino Canelas. Dos sentidos do marketing cultural. Revista Brasileira de Ciências da Comunicação. São Paulo: XXI (1):141- 149, janeiro/junho de 1998. 
majoritária dos recursos, em verdade, tem origem pública, através de renúncia fiscal.

Além da transferência de recursos públicos para o controle privado pura e simplesmente, no caso de não existirem certas cobranças e limitações na lei, o perigo subjacente do marketing cultural tem proximidade com aquele detectado na atuação estatal, a instrumentalização e o dirigismo da cultura. Se as empresas, que se utilizam do marketing cultural, não estiverem informadas por profissionais competentes na área cultural, o risco se torna imenso, pois inexistem condições para traçar sua política e selecionar os produtos e atividades culturais a serem apoiadas, respeitando sua relevância estética, social e/ ou de inovação. E a lógica cultural, ao invés de negociar sua afirmação frente a outras lógicas que perpassam a sociedade, outra vez pode ser atropelada por interesses extra e até contrários à cultura.

O mundo contemporâneo assistiu a um intenso desenvolvimento das indústrias da cultura, do entretenimento, do lazer e do turismo. Como anteriormente afirmado, este processo retém enormes convergências em uma fase mais atual. A potência, inclusive econômica, dessas indústrias tornou-se inegável. Elas estão entre as empresas mais lucrativas e de ponta em termos de crescimento na virada do milênio. $\mathrm{O}$ trabalho de Edson Farias $^{13}$, para lembrar um exemplo, demonstra cabalmente essa poderosa presença e convergência.

O efeito mais profundo da potência dessas indústrias, entretanto, está indiscutivelmente associado à sua capacidade de transformar-se no circuito cultural dominante no mundo contemporâneo. Se em outros países, como a França, o sistema escolar-uni- versitário ainda parece ter alguma possibilidade de contraposição a essa dominância, tensionando-a e mesmo tornando possível sua relativização, no Brasil parece cristalino que, desde o final dos anos sessenta, esse circuito se impôs como a modalidade cultural dominante no país. A leitura e a literatura foram fundamentais para a construção das "comunidades imaginárias" que conformaram as nações européias, como constatou Benedict Anderson. O cinema hollywoodiano teve, não resta dúvida, um lugar essencial para expressar configurando o american way of life.

Em nosso país, este papel integrador e doador de uma identidade compartilhada parece ter sido produzido pelas telenovelas e pelo Jornal Nacional, em uma demonstração contundente da hegemonia alcançada pela indústria midiática no Brasil.

A poderosa presença de uma lógica própria, com interesses muito específicos e por demais marcados pelo lucro, que tudo busca reduzir ao registro da forma mercadoria, e o caráter abrangente desse circuito cultural apontam para o seu perigo mais proeminente: sua capacidade de absorver as outras manifestações culturais, reduzindo-as ao seu mínimo denominador comum - a cultura mercantil leve, na qual a lógica dominante deixa de derivar do campo cultural para perigosamente ser comanda- 
da, em plenitude, por uma dinâmica mercantil, sem mais. Isso, no entanto, não implica a impossibilidade da persistência e mesmo, em alguns exemplos específicos, do predomínio de um vetor mais expressivamente cultural. Acontece que nessas empresas a produção majoritária encontra-se subsumida ao capital, reproduzindo uma lógica de indústria cultural.

\section{SOCIEDADE CIVIL E CULTURA}

Apesar dessa constatação, uma política cultural atualizada não pode abandonar a reflexão crítica no relacionamento com as mídias e as indústrias da cultura. Essa relação, complexa e problemática sem dúvida, não pode significar submissão, nem tampouco desconhecimento da existência e da lógica especificamente existente nas indústrias da cultura. Da satisfatória resolução dessa relação, absolutamente atual, inevitável e central depende, em razoável medida, o êxito e a pertinência das políticas culturais almejadas.

\section{Outro componente \\ imprescindível para a promoção cultural recebe o nome de sociedade civil.}

ciedade civil, através de suas diferenciadas instituições, pode costurar um vínculo essencial entre cultura e excluídos, trabalhadores, minorias, enfim, grupos sociais os mais diferenciados. Os sindicatos, as associações de bairro, as associações em geral, os movimentos sociais, as ONGs, todos esses atores da sociedade civil têm um lugar de destaque para esta conexão, vital para uma política cultural que se pretenda democrática.

No mundo contemporâneo, caracterizado pela multiplicidade de sujeitos políticos e fontes identitárias, não há mesmo possibilidade de políticas culturais atualizadas e democráticas sem que seja estabelecida uma interlocução com os amplos e plurais setores aglutinados por essa expressão política essencial: a sociedade civil. Ela pode ser um contraponto fundamental às pretensões do Estado ou do mercado de funcionar, um ou outro, como regulador plenipotenciário da vida social, inclusive da cultura. Em verdade, a sociedade civil, e sua imanente pluralidade, pode ser o alicerce de construção de uma vida pública, porque comum e compartilhada por todos, e de um setor público da sociedade, porque governado por interesses comuns e plurais, configurando ambientações imprescindíveis para tornar possível erigir uma política cultural democrática.

Mas uma política cultural democrática obrigatoriamente tem de reconhecer outra pluralidade: a diversidade de públicos com visões e interesses diferenciados, que compõem a contemporaneidade. Uma política cultural sintonizada com o presente não pode olvidar essa complexidade de públicos. Qualquer tentativa de aniquilar tal complexidade atinge violentamente o caráter democrático pretendido. Entretanto, 
em uma sociedade desigual como a brasileira, a atuação frente aos públicos não pode se limitar ao respeito à sua pluralidade. Trata-se mesmo de consolidá-la através da inclusão de amplíssimos públicos excluídos do consumo e da criação culturais, uma das faces mais perversas da exclusão social que conforma esse injusto Brasil.

A inclusão dos públicos deve, em uma primeira dimensão básica, ser capaz de introduzi-los na cultura letrada. A ponte essencial entre as políticas culturais e educacionais, tão desprestigiada entre nós, emerge aqui em toda a sua plenitude.

Em uma outra dimensão, trata-se de ampliar e tornar reflexiva a cultura audiovisual dos públicos excluídos. Diversificar as experiências audiovisuais, hoje quase circunscritas à televisão, através do cinema, do vídeo, da pintura, da escultura, do design, dos materiais infográficos, dos novos modelos televisivos, do teatro, da dança etc., representa um requisito de base. Mas não só ampliar a experiência audiovisual: permitir a emergência de reflexões e debates críticos sobre esses materiais, que perpassam esses públicos, considerando-os na condição de sujeitos potenciais de seu discurso.

Além da incorporação de enormes segmentos de públicos excluídos, uma política cultural, em estreita interação com a educacional, deve envidar esforços redobrados na formação de novos públicos, especialmente entre crianças, jovens e idosos. A atividade de formação de públicos deve ser mesmo um dos sustentáculos de uma política de cultura orientada por uma concepção radicalmente democrática. As escolas e as universidades podem ter aqui um atuação insubstituível, desde que adotem uma visão de formação mais integral, não adstrita apenas a um aprendizado in- telectual, mas voltem-se também para educar e expandir as sensibilidades e os valores sociais. Em suma, para formar um cidadão que, tendo uma especialidade, seja um sujeito político e cultural.

A organização dos diferentes públicos culturais igualmente deve ser contemplada em uma política consistente, pois a organização dos públicos e a expressão pública de suas demandas genuínas apresenta-se como um dado vital à democratização e ao pluralismo da cultura na sociedade.

A ampliação, formação, diversificação e organização dos públicos culturais, sem dúvida, produzirão um profundo impacto sobre a dinâmica cultural, possibilitando seu enriquecimento, sem precedentes, se combinados a uma política mais ampla de superação da exclusão social. Com essa nova base societária, uma pluralidade de manifestações culturais poderão ganhar vida e terem possibilidade de ser mantidas, em uma relação direta com o público. Por conseqüência, elas se tornarão mais independentes das benesses do Estado ou do patrocínio do mercado. Uma dinâmica realizada por uma lógica eminentemente cultural poderá fazer florescer a cultura, sem dúvida.

Por fim, a política cultural não pode olvidar os profissionais da cultura. A formação de profissionais da cultura - sejam eles criadores, divulgadores e organizadores - constitui-se como uma das metas a ser contemplada. A organização dos profissionais também deve ser almejada, ainda que a política cultural não possa ficar refém dessas organizações, pois o vício do corporativismo deve ser de todo modo evitado. Mas a intervenção dos profissionais da cultura no debate e na confecção das políticas culturais aparece como condição necessária para sua democracia, consistência e efetividade. 
Antes de concluir, cabe ressaltar, mais uma vez, a essencial conexão existente entre políticas de cultura e de educação. A atividade educacional não só forma os futuros profissionais da cultura, mas aparece como momento essencial da transmissão da cultura e da formação dos públicos. Assim, em boa medida, as questões culturais de um país têm uma estreita conexão com seu perfil educacional. Essa proximidade não pode ser tomada como mera identidade, sem mais. Tanto populações que não possuem uma educação formal têm cultura e podem produzir impressionantes monumentos civilizatórios, quanto uma população educada. A interação entre educação e cultura retém toda uma complexidade, que não pode nunca ser esquecida, sob pena de se recair em concepções assaz elitistas.

\section{EQUILÍBRIO DA POLÍTICA CULTURAL}

Restam alguns dilemas que podem ser expressos em pares bipolares marcadamente impregnados de contemporaneidade. O primeiro deles está vinculado diretamente a uma das características mais visíveis de nossa época: a relação entre o local e o global. Não existe política cultural possível que não tenha que enfrentar a glocalidade presente inclusive no campo cultural. Equacionar a interação inevitável entre os fluxos culturais globais e aqueles oriundos do local deve ser encarada como um dos nós centrais para a atualidade de uma política cultural. Nem o provincianismo do puro local, nem o internacionalismo do puro global podem se sustentar. Aqui vale lembrar o poeta
Gonzaguinha: "O equilíbrio é difícil, mas meu pé é da largura do arame". Parece ser esse o desafio: construir uma política cuja largura assegure o equilíbrio e equacione os fluxos, por vezes tão díspares e distintos. Mesmo porque a cultura só floresce na interação, no diálogo, na troca e nunca no isolamento ou na submissão. A idéia do isolamento ou da cópia, sem intercâmbio de sentidos, sempre violenta a cultura, pois aniquila o lastro vital que a anima: a diversidade é que torna possível, através da interação, crítica e complementar, o surgimento de novas dinâmicas de sentido, de novos dispositivos culturais.

Outro equilíbrio difícil diz respeito à relação entre o uno e o diverso. Ou melhor, entre identidade e pluralidade.

Historicamente as políticas culturais estiveram associadas à busca e à expressão de identidades, em geral de nações e de classes sociais.

Não só por essa relação histórica fica difícil dissociar cultura, identidade e políticas culturais. A cultura parece fadada a sempre expressar alguma identidade, a ter marcas de seus criadores, a exprimir traços entranhados nos sujeitos "transindividuais", como diria Lucien Goldmann ${ }^{14}$, que permitem a emergência das culturas. Como então forjar políticas culturais que, sem esquecer esse essencial enlace entre culturas e identidades, possa se pretender e assegurar uma pluralidade cultural? Não parece simples responder esta questão, mas ela se coloca no

14. GOLDMANN, Lucien. Crítica e dogmatismo na cultura moderna. Rio de Janeiro: Paz e Terra, 1973. 
cerne de uma política cultural em uma contemporaneidade atravessada pela proliferação possível de identificações, por um jogo de múltiplas identidades potenciais.

Diferente do tempo moderno, quando as vanguardas artísticas faziam a apologia do novo, da ruptura como mecanismo perpétuo de criação da cultura, os tempos atuais - pósmodernos para alguns, neo-modernos para outros - faz brotar em toda sua força a polaridade entre tradição e inovação. Tal pólo tem uma essencialidade derivada não só destes ares de questionamento e de mal-estar do moderno. Combinar componentes da tradição e da inovação, sem dúvida, torna-se outro desafio de envergadura de uma política cultural contemporânea, pois hoje parece tranquuilo acreditar que a cultura não se refere só à tradição, nem também à inovação, antes ela manifesta-se nessa zona de fronteira, como um diálogo tenso, uma intertextualidade, que tece tradição e inovação, de modo sempre singular, em cada dado cultural.

Por fim, um quase eterno dilema de qualquer política cultural e, inclusive, de uma

Resumo: $\mathrm{O}$ autor discute aspectos polêmicos e importantes para a promoção de uma política cultural. Inicia discutindo o papel do intelectual na produção de cultura para ressaltar a importância de atores sociais como Estado, setor privado e sociedade civil. Defende a presença do Estado na formulação de politicas culturais, destacando seu papel regulador entre os interesses democráticos do conjunto da sociedade, os direitos da coletividade e os interesses mercantis privados. Destaca a importância da escola e das entidades da sociedade civil, defendendo o equilibrio de uma política cultural que leve em conta - global e o local, a tradição e o novo, nunca se esquecendo de que uma política cultural deve buscar abranger a diversidade de manifestaçōes da sociedade.

Palavras-chave: politica cultural, marketing cultural, Estado, sociedade civil, intelectual que se imagine contemporânea: a dosagem precisa entre o dirigismo e o espontaneísmo, imanentes e necessários à promoção da cultura. A questão básica aqui pode ser formulada como o grau de estímulo adequado para animar a vida cultural, sem subestimar nem superestimar a dinâmica inerente às manifestações e aos sujeitos culturais. A sensibilidade e a informação parecem ser condições de um equacionamento satisfatório do tema. Aliás, elas são condição para qualquer intervenção cultural democrática e enriquecedora.

Os dilemas para uma política cultural adquirem na contemporaneidade uma abrangente envergadura. Eles acolhem um conjunto complexo de dimensões, muitas delas recentes, outras já tradicionais, mas todas elas em um movimento acelerado. Ser perspicaz na observação dessas mutações, compreendê-las agilmente e propor soluções inovadoras e adequadas para esse megaconjunto de questões não parece ser uma exigência fácil. Mas, como dizia outro poeta, o difícil é a vida e seus problemas.

(Contemporaneous cultural policy)

Abstract:The author discusses controversial and important aspects in the promotion of a cultural policy. He starts by discussing the intellectual's role in producing culture in order to emphasize the importance of social actors such as the State, the private sector and the civil society. He defends the presence of the State in formulating cultural policies, highlighting its regulating role in the democratic interests of the society as a whole, the rights of the collectivity and the private mercantile interests. The article stresses the importance schools and civil society entities have, defending the balance of a cultural policy that considers both global and local, tradition and novelty, never forgetting that cultural policy must cover the diversity of society's manifestations.

Key words: cultural policy, cultural marketing, State, civil society, intellectual 